\title{
The influence of Anglo-American theoretical models on the evolution of the nursing discipline in Spain
}

\author{
Olga Rodrigo \\ School of Nursing, Campus Docent Sant Joan de Déu, University of Barcelona \\ Esplugues de Llobregat, Barcelona, Spain \\ Jordi Caïs \\ Department of Sociology and Organizational Analysis, University of Barcelona \\ Barcelona, Spain
}

Cristina Monforte-Royo

Nursing Department, School of Medicine and Health Science. Universitat Internacional de Catalunya, Sant Cugat del Vallés, Barcelona, Spain

\begin{abstract}
In Spain, the introduction of the new Diploma in Nursing in 1977 saw the role of nurses shifting from that of medical assistants with technical skills to being independent members of the healthcare team with specific responsibility for providing professional nursing care. Here we analyse the evolution of the nursing profession in Spain following the transfer of nurse education to universities, doing so through interviews with the first generation of academic tutors. This was a qualitative study using the method of analytic induction and based on the principles of grounded theory. Participants were selected by means of theoretical sampling and then underwent in-depth interviews. Steps were taken to ensure the credibility, transferability, dependability and confirmability of data. The main conclusion of the analysis is that there is a gap between a theoretical framework borrowed from the Anglo-American context and a nursing practice that, in Spain, has traditionally prioritised the application of technical procedures, a role akin to that of a medical assistant. It is argued that a key factor underlying the way in which nursing in Spain has evolved in recent decades is the lack of conceptual clarity regarding what the role of the professional nurse might actually entail in practice.
\end{abstract}

Keywords: grounded theory, twenty-first century history, nursing, nursing theory, professional role, Spain 


\section{BACKGROUND}

The year 1977 is a milestone in the history of nursing in Spain, as it was then that nurse education became the responsibility of universities and a new Diploma in Nursing was established. This resulted in the role of the Spanish nurse shifting from that of a medical assistant with technical skills (Domínguez-Alcón, 1986, p. 103; Sellán, 2010, p. 241 ) to being an independent member of the healthcare team with specific responsibility for providing what was termed "professional nursing care"(Garcia \& Martinez, 2001, p. 185).

In her analysis of the history of the nursing profession, Rousseau (1997) argues that the recognition of nursing as a discipline implied a conceptual shift away from the idea of the 'model nurse' for whom caring is a vocation — as in the case of Spanish nursing prior to 1977 — to a concept of care based on theoretical models of nursing, such that care becomes a science. This process occurred much earlier in some countries than in others. In the English-speaking world, for instance, important developments in the nursing profession began to take place in the early part of the twentieth century, leading to increased training and skills development for nurses, as well as a more explicit definition of the principles of practice (Bullough \& Bullough, 1981). Thus, by the time the system in Spain began to change in the 1970s, the theoretical framework already developed in the Anglo-American context was there to be drawn upon. What is unclear, however, is to what extent the availability of this theoretical body of knowledge influenced the development of the nursing discipline in Spain. 
In Spain, nursing began to be officially recognised as a profession in 1857 , when the government of the day passed a public Education Law that established three categories: practitioner, matron and nurse (Boletín Oficial del Estado [Official Gazette of the Spanish government], 1857). Almost a century later, the Royal Decree of 27 June 1952 (Boletín Oficial del Estado, 1952) unified these roles into a single nursing qualification known as ATS (Technical Healthcare Assistant). Despite the new qualification, however, the role of the nurse continued to be that of a medical assistant, with the emphasis on the application of technical procedures for treating the patient's illness (Hernández, 1995).

At the beginning of the 1960s, and influenced by developments in the nursing profession in the USA and Canada, a current of opinion began to form in Spain calling for nursing to become a university-based discipline (García \& Martínez, 2001). Subsequently, in 1970, the new Education Law (Boletín Oficial del Estado, 1970) considered two possibilities for the ATS qualification: integrating it within the country's already discredited vocational training system or raising its status to university level. In response, nurses across the country demonstrated in large numbers in favour of the latter option (Sellán, 2010, p. 242), and eventually, in July 1977, the responsibility for nurse education was transferred to universities, a move that saw the ATS qualification being replaced with the new Diploma in Nursing (Boletín Oficial del Estado, 1977a).

The Academic Advisory Committee that was set up in order to establish the content of the new training syllabus envisaged that nurses who obtained the diploma would have a specific role within the healthcare team (Santo-Tomás, 2000, p. 105), namely providing "professional nursing care” (García \& Martínez, 2001, p. 185). When 
legislation regarding the syllabus to be followed by the new schools of nursing was published in November 1977 (Boletín Oficial del Estado, 1977b), it included a new core subject entitled Fundamentals of Nursing, which had not previously formed part of the ATS qualification. The focus of this new subject was the specific theoretical content that nurses would need to apply in practice under their new professional role (Germán, 2013, p. 196; Santo-Tomás, 2000, p. 105).

Another provision set out under this legislation was that existing nurses in possession of the ATS qualification would be called upon to teach specific subjects such as the aforementioned Fundamentals of Nursing (Sellán, 2010, p. 244). This meant that they would be required to teach the theoretical content related to the provision of "professional nursing care" without themselves having received prior training or experience of this kind. How this first cohort of nurse teachers went about constructing the discipline in the academic context, and how the new theoretical body of knowledge influenced the clinical practice of subsequent generations of Spanish nurses, are questions that have yet to be answered.

\section{METHOD}

Taking as its starting point the experience of the first wave of ATS nurses who became teachers on the new Diploma in Nursing courses, the present study seeks to analyse the evolution of the nursing discipline in Spain following the transfer of nurse education to universities, and to explore how the new theoretical body of knowledge was constructed.

This was a qualitative study using the method of analytic induction, in which the formulation of an initial hypothesis was followed by the selection of extreme cases (Katz, 2001; Borobia, 2004). Interviews with participants were analysed using 
interpretive description (Thorne, Kirkham \& MacDonald-Emes, 1997; Thorne, Kirkham \& O'Flynn-Magge, 2008).

Participants were selected by means of theoretical sampling (Katz, 2001). The number of participants to be recruited was established according to the criteria of sufficiency (Seidman, 2013), with sampling ending when theoretical saturation was reached (Strauss \& Corbin, 2002; Strauss \& Corbin, 2015).The main inclusion criterion was that participants should have been employed as nurses with the ATS qualification at the point when nurse education was transferred to universities. They were recruited from different regions of Spain with the aim of achieving maximum variability of contexts.

The final sample comprised eight participants (Table 1) who were interviewed between March 2013 and May 2015. The eight participants had between 10 and 35 years of experience as nurse teachers. The first six participants were recruited during the initial sampling, and on the basis of the interviews conducted with them, two possible extreme cases were subsequently identified. As no new information was gained through these two interviews it was concluded that theoretical saturation had been reached. Interviews lasted between 60 and 90 minutes.

Data were gathered through in-depth interviews designed in accordance with the recommendations of Seidman (2013), that is, the sequential exploration of three topics in order to help induce the participant's experience. Table 2 shows the guidelines for the topics to be explored. Participants were recruited through the university nursing schools in Spain with which the research team had contact. Interviews were conducted by the first author, who introduced herself to participants as a nurse teacher. The initial contact with potential participants was via email and involved providing them with information about the study and requesting their participation. The date and time for a face-to-face 
interview was then agreed, in a place of the participant's choosing (which in all cases was their place of work). Written informed consent was obtained at the beginning of each interview, prior to any kind of data collection.

The study was approved by the Research Ethics Committee of the Universitat Internacional de Catalunya. All participants were informed that participation was voluntary, and they all signed informed consent. The anonymity and confidentiality of data was ensured at all times.

Data were analysed using a grounded theory approach based on theoretical sampling and the constant comparative method (Strauss \& Corbin, 2002). The first step involved the open or substantive coding of data, in which fragments of discourse were linked to coding labels. This was followed by focused coding, in which we sought to identify the most significant and/or frequent codes in order to define the emergent categories. Based on the outcome of this focused coding we then drew up provisional categories, specifying their properties and dimensions (axial coding). The application of a coding paradigm throughout the analytic process facilitated the subsequent establishment of relationships between categories and enabled the final theoretical narrative to be produced. In addition, a series of memos were generated in order to provide support for the entire analytic process (Charmaz, 2006).

In order to ensure the study's credibility the results are illustrated with verbatim quotations (see Table 3) from the interviews with participants. Additionally, an internal audit was performed of the decisions made within the research team, coupled with an external audit conducted by an expert in qualitative methodology. As regards transferability, we clearly described the sampling context (see Table 1) and considered the results as working hypotheses that are not susceptible to generalisation. To systematise and support the analytic process, work standards were used in conjunction 
with the ATLAS.ti 7.1 software (for operative support) during the entire research process. Finally, internal and external audits were carried out so as to ensure the confirmability of results.

\section{FINDINGS}

The initial discourse analysis revealed four categories that described the evolution and construction of nursing as a professional discipline in Spain following the transfer of nurse education to universities. These categories were: transfer of nurse education to universities as a response to social and historical needs; a body of theoretical knowledge originating in the Anglo-American context; a model of socialisation based on the supremacy of technical procedures; and a gap between theory and a technically-based practice.

Application of the constant comparative method to these four initial categories yielded a core category that could account for how nursing as a professional discipline has evolved in Spain following the transfer of nurse education to universities. This core category was: a lack of conceptual clarity regarding the role of the professional nurse (Figure 1). In the following sub-sections we discuss each of these categories. In the case of the four initial categories we link the discussion to the verbatim quotations presented in Table 3; for example, P5:1 in the text indicates that the point being made is supported by quotation P5:1 for the corresponding category in Table 3.

\section{Transfer of nurse education to universities as a response to social and historical needs}

There are three key factors that can help explain why nursing in Spain saw its status raised to university level rather than become incorporated into the already discredited vocational training system of the day: the country's transition to democracy 
following the death of Franco in 1975, the fact that nurses had skills that went beyond the vocational level, and greater independence for women in society.

The swearing in of King Juan Carlos of Spain in 1977 marked the beginning of the country's transition to democracy after four decades of dictatorship (Germán 2013, 32). In the process that followed, one of the things that the Spanish people called for was the establishment of universal health care.(P5:1)

The new system of public and universal health care opened up a range of opportunities for nurses with the ATS qualification, who saw their employment prospects boosted by the need for nurses with greater technical competence, a sense of responsibility and the capacity for decision making.(P5:2)(P5:3)

A key aspect of this process was the greater autonomy being granted to women in Spanish society, which inevitably had an impact on the predominantly female nursing profession.(P4:4)

\section{A body of theoretical knowledge originating in the Anglo-American context}

In Spain, the initial body of nursing knowledge was based on two distinct types of care, which we shall refer to here as 'general care' and 'traditional nursing care'. As a result of the new university-based training, however, nurses were expected to apply what was termed "professional nursing care", which according to Medina (1999) implied the scientific transformation of the other two types of care.

The notion of 'general care' derives from human nature itself; its goal is to enable the growth of the species (Watson, 1997, 2006) and it is closely linked to motherhood and, therefore, to the role of women in society (Celma \& Acuña, 2009; Hernández , 1995).(P4:1)

Traditional nursing care, as practised by nurses in hospitals, went beyond this level of general care, however, and was based on intuition and tradition. As no specific 
records had to be kept for this aspect of care, there was generally no written account of what it actually entailed in practice. Importantly, Celma \& Acuña (2009) point out that this tends to be the case even today in Spain, since many of the tasks that form part of professional nursing care are not usually recorded as they are regarded as being less important than are those tasks that involve the application of some technical procedure (e.g. giving injections).(P3:2)

Nursing in Spain had traditionally been seen as a vocation in which caring was based on the principle of Christian charity (Miró-Bonet, 2008), thereby epitomising the idea of the 'model nurse' who cares out of duty (Rousseau, 1997). This, together with the gender stereotype that saw the caring role as being inherent to women, meant that many of the professional tasks carried out by nurses in Spain were often overlooked.

(P4:3)

The goal of the new university-based training programme was that nurses would become core members of the healthcare team with specific responsibility for providing professional nursing care based on the application of certain theoretical models. However, the lack of nurse teachers with the academic background required to develop the corresponding curricular content, which implied giving a scientific foundation to the caregiving role, meant that this knowledge had to be borrowed from the AngloAmerican context, in which the nursing discipline had already developed along these lines (Miró-Bonet, 2010).(P6:4).

However, the difficulty of accessing the scientific literature in English, coupled with the limited knowledge of this language among nurse teachers in Spain, meant that the emphasis was placed on those works that had already been translated into Spanish. This would seem to be why, among the extensive scientific literature available at the time, that the model chosen was that described by Virginia Henderson.(P2:5) 
The lack of academic training and experience in the application of scientificallyfounded professional care made it difficult for those charged with teaching the Fundamentals of Nursing to integrate theoretical models of nursing into health care practice.(P4:6)

The lack of integration between theory and practice led to nurses undervaluing the specific contribution that professional nursing care could make to society. As Celma \& Acuña (2009) point out, nurses in Spain continued to prioritise more technical tasks, to the detriment of other aspects of the caring role. An additional factor here is that a model of health care, whether in the USA or elsewhere, that places the emphasis on costs, technology and medical science leaves little room for nurses to exercise an independent caring role. Asargued by Warelow et al. (2008), nurses will only become aware of the value of caring when they have enough time, within their daily work routines, to carry it out and to witness the benefits.(P1:7)

\section{A model of socialisation based on the supremacy of technical procedures}

In Spain, the nursing discipline has evolved within a model based on the supremacy of technical procedures. One of the reasons for this is that almost all the newer generations of nurses (i.e. those who have obtained the university diploma) have received their academic and practical training from older colleagues in possession of the previous ATS qualification, which placed much greater emphasis on the performance of technical tasks. An additional factor is that nurses tended to ignore the theoretical content they were taught on the Fundamentals of Nursing course, as it was seen as being of little relevance to what they perceived as their real training needs in the practical setting. This meant that although the new generations of nurses were exposed 
at university to theories and models of nursing, the model of socialisation in practice continued to be that based on the supremacy of technical procedures. $(\boldsymbol{P} 4: 1)$

As noted above, a key reason for this was the fact that for many years most of the teachers linked to the Diploma course, both academically and on placement, had themselves been trained under the more technically-oriented ATS programme.(P4:2)

In order to encourage an attitude of acceptance among currently employed ATSqualified nurses of the new diploma students on placement, a grandparenting scheme was established, whereby the former could bring their knowledge up to date and, upon successfully passing the corresponding university exam, have their qualification supgraded to Diploma status (Boletín Oficial del Estado, 1980a, 1980b).(P5:3)

However, the urgency with which large numbers of ATS nurses had to be accredited meant that the grandparenting scheme had a number of shortcomings. Notably, it had to be implemented in a distance-learning format and over a period of time that was too short to cover all the new curricular content. (P6:4)

There were also irregularities in terms of the minimum standards required to pass the accreditation exam, which differed across the different regions of Spain.(P5:5) All these factors combined to undermine the extent to which the newly upgraded older nurses incorporated the new theoretical content into their actual practice. Furthermore, those teachers on the new Fundamentals of Nursing course who had been trained according to Anglo-American models did not believe that theories and models of nursing needed to be underpinned by practical experience. This likely led to a professional culture in which nurses were instructed in theoretical models that were rarely applied in practice.(P1:6)

Important changes in the Spanish health system, including the reform of primary health care (Boletín Oficial del Estado, 1984), forced the older generations of ATS 
nurses to prioritise training in order to acquire new skills. In this context, the teachers on the Fundamentals of Nursing course came to be seen as an academic elite with little or no grasp of clinical reality or the needs of nurses at the time. This kind of perception is highlighted in the study by Corlett (2000), who noted that nurse teachers frequently seek to introduce theoretical ideals that are impossible to implement in clinical practice.(P6:7)

\section{Gap between theory and a technically-based practice}

Application of the new body of knowledge led to a gap between theory and practice ( Arreciado \& Isla, 2015; López-Parra et al., 2006), which in turn generated a lack of motivation among both nurse managers and clinical nurses when it came to applying the new theories and models in everyday practice. (P4:1)

The introduction of theoretical models of nursing in an academic context that was seen as being cut off from the realities of nursing in Spain led to a widespread reluctance among nurses to implement these models in practice. $(\boldsymbol{P 4 : 2})$

One of the consequences of this was that the whole approach to nursing was applied in a mechanical way. In this respect, one might say that the nursing discipline in Spain has been characterised by a lack of critical reflection on clinical practice.(P4:3)

Another factor contributing to the gap between theory and practice is the lack of willingness on the part of clinical nurse managers to implement the new approach to nursing. However, developments in science in general, leading to a more complex and holistic approach to patient care, are seen as likely facilitators of change in this regard.(P4:4)(P4:5)

Interestingly, the gap between theory and practice also appears to be closing among the newest generations of nurses. In fact, the clinical practice in some health care 
settings is now more advanced than the theory that is being taught in the classroom. (P2:6)

A higher academic level among nurses, the availability of a shared nursing language and greater experience in the use of protocols that facilitate application of the new approach are seen as key factors driving these changes. $(\boldsymbol{P} 4: 7)(\boldsymbol{P} 2: 8)$

It is worth noting, however, that according to the study by Arranz (2015) on the use of conceptual models, nursing process and a standardised language, the fact that more Spanish nurses are now members of scientific societies has not led to an increased use of such tools among the profession.

\section{Lack of conceptual clarity regarding the role of the professional nurse}

Although almost four decades have now passed since nurse education in Spain was transferred to universities there continues to be a lack of conceptual clarity regarding what the proposed 'professional nursing care' actually entails in practice. This situation would seem to be the result of three factors: 1) a body of theoretical knowledge - borrowed from the Anglo-American context — that does not adequately match the needs of Spanish nurses in practice; 2) an insufficient academic background among the older generations of ATS nurses who acted as teachers on the university diploma course; and 3) important irregularities in the process of upgrading and accrediting the qualifications of ATS nurses in general (a process that was seen as key in relation to the hospital-based training that would be received by the newer generations of nurses on the diploma course).

Together, these factors fostered a disparity between the theory taught in university classrooms and everyday clinical practice (Arreciado \& Isla, 2015; LópezParra et al., 2006), leading to a mechanical application of the tools and concepts derived 
from the Anglo-American models and, ultimately, to a lack of reflection on nursing practice. These tools proved to be ill-suited to the model of nursing that was required to meet the needs of a changing society in Spain. However, the gap between theory and practice now appears to be closing among the newest generations of nurses, and there appear to be a number of factors driving this change: the higher academic level being achieved by these nurses, including entry onto doctoral programmes; the use of a shared professional language among nurses; and the introduction of computerised systems that facilitate the use of nursing protocols.

\section{DISCUSSION}

The nursing discipline in Spain has found it difficult to incorporate models of nursing originating in the Anglo-American context into everyday health care settings. This is illustrated by the gap between the theory that is taught in university classrooms, which offers models and concepts for the provision of 'professional nursing care', and the technically-oriented practice of many Spanish nurses (Arreciado \& Isla, 2015; López-Parra et al., 2006), where critical reflection is often lacking. In relation to these issues, the present study has identified a series of factors that have either hindered or encouraged the conceptualisation of the professional nurse's role in Spain.

\section{Factors that have hindered the conceptualisation of nursing in Spain}

The first factor to consider is that when, in 1977, nurse education was transferred to universities, many of the tasks traditionally carried out by Spanish nurses were not formally recorded in writing. In addition, the new Diploma in Nursing required a syllabus that would provide a more scientific perspective on nursing care (García \& Martínez, 2001, p. 185). As a result, the body of knowledge that would underpin the 
new Fundamentals of Nursing course had to be borrowed from the Anglo-American context (Miró-Bonet, 2010), where the nursing discipline had already developed along these lines. A similar process had taken place during the 1950s and 1960s in Japan, where Anglo-American theories were used as the basis for the development of manuals on nursing theory and philosophy, which became known locally as Kangoron (Huch \& Hisama, 2001).

In this respect, it is important to note that the ideas of Virginia Henderson, as well as other Anglo-American theories of nursing, were not based on the tradition of 'women as carers', nor on what nurses were already doing in practice; rather, they drew upon the body of knowledge developed in other disciplines such as psychology (Rousseau, 1997). This may be one reason why historians have considered nursing to be an invisible profession, one for which there are no written records of many of the care tasks carried out by nurses. Thus, the Anglo-American theories of nursing, articulated in the form of models, were constructed not on the basis of the history of care ( Maggs, 1996) but, rather, by turning to a body of knowledge already developed by other disciplines.

The initial aim of the Anglo-American theories was to develop a series of constructs that could account for the everyday practice of nurses (Lister, 1997). According to Park (1996), a particular goal of these theories and models was to rid nursing of its association with a 'science of hygiene', whereby the cleaning role assigned to women in the home was extrapolated to the hospital setting. It was important, therefore, that the new models could withstand the intellectual scrutiny of the scientific community. One of the consequences of this was that nursing adopted a highly rationalist discourse, one rooted in the sameconcepts as medical practice (Lister, 1997); importantly, the risk of this kind of overlap continues to this day (Beedholm \& 
Frederiksen, 2015). These theoretical proposals therefore had only a weak relationship to the everyday care practices of nurses. On this point, Shaw (1993) argues that if the discipline of nursing is to become an applied science, then it must base its approach on actual nursing practice. Interestingly, Miró-Bonet (2010) points out that the use of Anglo-American conceptual models was one of the strategies used by Spanish nurses during the 1970s and 1980s in an attempt to obtain recognition as an independent profession, distinct from medicine.

Another factor to consider is the considerable academic gap between AngloAmerican nurses, who began to develop their theories in the 1950s (Shaw 1993), and the first generations of Spanish nurses with the ATS qualification (1955-1977), whose academic training lagged well behind until practically the 1980s (Germán, 2013, p.186). The difficulty of integrating the new theoretical concepts and the absence of any experience in applying them in practice meant that, in Spain, the Anglo-American models of nursing were implemented in a mechanical way, without thesort of reflective practice required in order to adapt them to the Spanish health care context.

This notion of 'reflective practice' is a term coined by Schön (1987) and it comprises two elements: 'reflection in action' and 'reflection on action' (Kinsella, 2009). In this respect, an interesting line of future research would be to investigate the extent to which those nurses who have been trained under the Diploma scheme (i.e. since 1977) continue to perform their tasks as originally defined (which would indicate a lack of reflective practice) or whether, on the contrary, they have been able to engage in 'reflection on action' and improvise new working routines. This ability to introduce new routines would contribute to a continued improvement of practice and would imply a capacity for 'reflection in action'. 
Another factor that has hindered the conceptualisation of professional nursing in Spain is the important irregularities that occurred during the process of upgrading and accrediting those nurses who had obtained the earlier ATS qualification (Boletín Oficial del Estado, 1980a, 1980b), as this made it difficult to integrate the new nursing practices. More specifically, the new generation of diploma-trained nurses were subject to a process of enculturation in which their older peers continued to apply a model based on the supremacy of technical procedures, thereby helping to perpetuate the idea of nurses as medical assistants. As Shaw (1993) argues, if nurses are to be socialised as — and to think like — nurses, then nursing studies need to be based on a nursing paradigm, not one that is proper to medicine.

A final factor that has hindered the conceptualisation of the nurse's role in Spain has to do with the important changes that the Spanish health care system underwent in the years following the transfer of nurse education to universities. Nurses were now required to develop new skills related to the reform of primary health care (Boletín Oficial del Estado, 1984) and to provide specialist care that was increasingly complex and which made use of new technology (Santo-Tomás, 2000, p. 93; Sellán, 2010, p. 220). The fact that nurses saw little value in a model of nursing that was difficult to apply in their everyday practice, coupled with the need to acquire the new skills they were now required to perform, helped to consolidate the gap between theory and practice. Interestingly, Engstron (1984) and Bramwell (1985) note that a similar gap was also present in the Anglo-American context during the same period, as illustrated by the debate over whether theory was 'of nursing' or 'for nursing'.

A further point to take into account here concerns the number of nurses working in Spanish hospitals (Ferrús et al., 2006), which was estimated tobe 35\% below the European average (Garcia et al., 2008). This is another factor that can help explain why 
Spanish nurses prioritised a more technical role over the proposed 'professional nursing care', the latter being based on theories and models that they saw as difficult to apply in practice.

\section{Factors that have encouraged the conceptualisation of nursing in Spain}

Despite the limiting factors described in the previous section, there is also evidence from some health care settings that the gap between theory and practice is beginning to be closed, thus enabling a better conceptualisation of the role of nurses in Spain. The main drivers of this process appear to be the use of a shared professional language among nurses and the availability of tools that promote the practical application of the theoretical models of nursing.

The shared language reflects specific knowledge that nurses are expected to have, such as that recommended by the North American Nursing Diagnosis Association (NANDA), the Nursing Interventions Classification (NIC) and the Nursing Outcomes Classification (NOC) (Lunney et al., 2004). The use of classifications and protocols such as these has both advantages and disadvantages. As regards the benefits, Hayakama's theory of language (Hayakawa \& Hayakawa, 1990) would suggest that their use facilitates communication, cooperation and collaboration among professionals (Lunney et al., 2004), thereby encouraging the establishment of professional identity (Del Pino, 1998). In addition, the possibility of providing evidence-based care helps to drive conceptual advances within the nursing discipline (Bulechek, 2014; Moorhead \& Johnson, 2014). Another advantage of a shared language is that its use helps to increase the social visibility of nursing as a profession (Del Pino, 1998).

As for the disadvantages, Mitchell (1991) argues that the definitions of the terms used in these classifications or sets of guidelines are unlikely to capture the complexities 
of clinical practice. Likewise, SmithBattle \& Diekemper (2001) suggest that their use may misconstrue the experience of nurses, thereby distorting their view of clinical reality (Lunney et al., 2004).

Other authors have sought to see both sides of the argument, suggesting that while protocols of this kind can be highly useful for guiding clinical practice, especially among less experienced professionals, they should not be seen as a replacement for critical reflection or thorough assessment of the patient's specific condition (Travale, 2007). This opens up an interesting avenue for future research in Spain, in that it would be useful to explore whether, in those settings where standardised protocols and guidelines are used, nurses engage in critical reflection or continue to apply the AngloAmerican models in a mechanical way. If the latter proved to be the case, this would mean that these models of nursing, whose principal purpose is to raise the profile of nurses within the health care system, are still being applied in a way that undermines the development of Spanish nursing as an applied science.

As a final point regarding the use of nursing practice tools, a systematic review conducted in 2003 (Currell \& Urquhart, 2003) found no evidence of effects on practice that could be attributed to changes in nurse record systems. The authors of this review also suggested that the paucity of studies of sufficient methodological rigour highlighted the need for both randomised trials and studies of a more qualitative nature (Currell \& Urquhart, 2003), which in the Spanish context would help to determine the extent to which such systems are able to facilitate a clearer conceptualisation of the nurse's role.

\section{LIMITATIONS}

The main limitation of this study is that two of the authors are themselves members of the nursing profession, which may have influenced both the gathering of 
data and the process of analysing the interview transcripts. In an attempt to minimise this potential bias, we held — throughout the data gathering and analysis process several inter-analysis meetings both within the research team and in collaboration with an external consultant (Cornejo, Besoaín \& Mendoza, 2011).

\section{CONCLUSION}

The nursing profession in Spain suffers from a lack of conceptual clarity regarding the nurse's role. This would seem to be the result of the gap between theory — as taught in university schools of nursing, and based on models borrowed from the Anglo-American context - and the everyday practice of Spanish nurses, which still places considerable emphasis on technical procedures, and where critical reflection is often lacking. When, in 1977, nurse education in Spain was transferred to universities the models of nursing already developed in the Anglo-American context were seen as a way of advancing the discipline along more scientific lines. This process was hindered, however, by a number of factors, notably the lack of written records regarding what Spanish nurses actually did in practice and the lack of a sufficient academic background among the first generations of nurse teachers on the new Diploma in Nursing course (Medina, 1999). Interestingly, Burgess and Purkis (2010) identified similar training limitations among Canadian nurses when it came to aspects of role development such as carrying out research in their area of knowledge.

The fact that the Anglo-American theories and models drew upon developments in other disciplines (e.g. psychology) rather than being founded on the tradition of nursing care in that context (Maggs, 1996) has made it difficult forthem to be transferred to health care settings in Spain. A key factor here is that they were often models 'of nursing' rather than 'for nursing' (Shaw,1993), and this meant that the 
theory being taught in universities was frequently applied in a mechanical way by Spanish nurses, whose role in practice continued to be akin to that of a technicallyskilled medical assistant. The main consequence of this gap between theory and practice has proved to be a lack of conceptual clarity regarding what 'professional nursing care' based on reflective practice actually entails. A related disparity has been observed in countries such as Canada (Warelow et al., 2008) and the USA (Watson, 2006), whose health systems give priority, for financial reasons, to technology and medical science, leaving nurses relatively few opportunities to implement person-centred care in practice. Other authors go as far as to argue that this is a problem affecting nursing the world over and that it results from the dominance of American thought, which has led to the Americanisation of other countries' theories and models (Holt, Barrett, Clarke \& Monks, 2000).

Despite these obstacles, the gap between theory and practice in Spain appears to be closing, driven by factors such as the use of common classifications and protocols (e.g. NANDA, NIC, NOC) that facilitate understanding and communication of theoretical knowledge among professionals, as well as the availability of software applications that make it easier to implement the tenets of 'professional nursing care' in practice. 


\section{REFERENCES}

Arranz, S. (2015). Modelos conceptuales, metodología, lenguaje estandarizado y su relación con el asociacionismo científico en enfermería [Conceptual models, methodology and standardised language and their relationship to the presence of scientific associations in nursing]. (Unpublished doctoral thesis). Madrid: Universidad Complutense de Madrid. Retrieved from: http://eprints.ucm.es/34363/1/T36686.pdf

Arreciado, A., \& Isla, M. (2015). Theory and practice in the construction of professional identity in nursing students : a qualitative study. Nurse Education Today, 35(7), 859-863. doi:10.1016/j.nedt.2015.03.014

Beedholm, K., \& Frederiksen, K. (2015).The process of Danish nurses' professionalization and patterns of thought in the 20th century. Nursing Inquiry, 22(2), 178-87. doi:10.1111/nin.12079

Boletín Oficial del Estado [Official Gazette of the Spanish Government]. (1857). Ley Moyano de instrucción pública de 9 de septiembre de 1857 [Law on public education of 9 September 1857].

Boletín Oficial del Estado [Official Gazette of the Spanish Government]. (1952). Decreto de 27 de junio de 1952 [Decree of 27 June 1952].

Boletín Oficial del Estado [Official Gazette of the Spanish Government]. (1970). Ley General de Educación [General Law on Education].

Boletín Oficial del Estado [Official Gazette of the Spanish Government]. (1977a). Real Decreto 2128/1977 [Royal Decree 2128/1977].

Boletín Oficial del Estado [Official Gazette of the Spanish Government].(1977b). Orden Ministerial de 22 de octubre de 1977 [Ministerial Order of 22 October 1977].

Boletín Oficial del Estado [Official Gazette of the Spanish Government]. (1980a). Orden del 15 de julio de 1980 [Order of 15 July 1980].

Boletín Oficial del Estado [Official Gazette of the Spanish Government]. (1980b). Real Decreto 111/1980 de 11 de enero [Royal Decree 111/1980 of 11 January].

Boletín Oficial del Estado [Official Gazette of the Spanish Government]. (1984). Real Decreto 137/84 sobre estructuras básicas de salud [Royal Decree 137/84 on basic health structures].

Borobia, R. (2004). La Hipótesis en estudios cualitativos. El caso de la inducción analítica en una investigación sobre adolescencia [The hypothesis in qualitative research: The use of analytical induction in a study of adolescence]. Revista Pilquen, Sección Ciencias Sociales, V(6), 1-12. 
Bramwell, L. (1985). Nursing science: retrospect and prospect. The Canadian Nurse, $81(3), 45-48$.

Bulechek, G. (2014). Clasificación de intervenciones de enfermería (NIC) [Nursing Interventions Classification (NIC)]. Barcelona [etc.]: Elsevier. Retrieved from http://ccuc.cbuc.cat/record=b5859653 S23*cat

Bullough, B., \& Bullough, V. (1981). Educational problems in a woman's profession. Journal of Nursing Education, 20(7), 6-17. doi:10.3928/0148-4834-19810901-03

Burgess, J., \& Purkis, M. E. (2010). The power and politics of collaboration in nurse practitioner role development. Nursing Inquiry, 17(4), 297-308. doi:10.1111/j.1440-1800.2010.00505.x

Celma, M., \& Acuña, A. (2009). Influencia de la feminización de la enfermería en su desarrollo profesional [Influence of a predominantly female workforce on the development of nursing as a profession]. Revista de Antropología Experimental, 9 (9), 119-136.

Charmaz, K. (2006). Constructing Grounded Theory: A Practical Guide through Qualitative Analysis. London: Sage Publications.

Corlett, J. (2000). The perceptions of nurse teachers, student nurses and preceptors of the theory-practice gap in nurse education. Nurse Education Today, 20(6), 499505. doi:10.1054/nedt.1999.0414

Cornejo, M., Besoaín, C., \& Mendoza, F. (2011).Desafíos en la generación del conocimiento en la investigación social cualitativa contemporánea [Challenges for the generation of knowledge in contemporary, qualitative social research]. Forum: Qualitative Social Research, 12 (1), Art. 9

Currell, R., \& Urquhart, C. (2003). Sistemas de registro de enfermería: efectos sobre la práctica de la enfermería y resultados en la asistencia sanitaria. [Nursing record systems: effects on nursing practice and health care outcomes] Cochrane Plus Library. Retrieved from

http://www.bibliotecacochrane.com/BCPGetDocument.asp?DocumentID=CD002099

Del Pino, R. (1998). Líneas de investigación en diagnósticos enfermeros [Lines of research in nursing diagnoses].Correo Asociación Española de Nomenclatura, Taxonomía y Diagnóstico de Enfermería, II(3), 4-5.

Domínguez-Alcón, C. (1986). Los cuidados y la profesión enfermera en España [Care and the nursing profession in Spain]. Madrid: Ediciones Pirámide.

Engstrom, J. L. (1984). Problems in the development, use and testing of nursing theory. The Journal of Nursing Education, 23(6), 245-251.

Ferrús, L., Gil, M., Gutiérrez, C., Estrem, M., \& Escobar, M. (2006).Recomanacions per la dotació d'infermeres a les unitats d'hospitalització. Factors que influencien la pràctica infermera [Recommendations for nurse staffing levels in hospitals: 
Factors that influence nursing practice]. Barcelona: Consell de Col· legis de Diplomats en Infermeria de Catalunya.

García, C., \& Martínez, M. L. (2001). Historia de la enfermería: evolución histórica del cuidado enfermero [History of nursing: the historical development of nursing care]. Madrid: Elsevier.

García, J., Carmona, P., Dieguez, B., Langreo, V., Reoyo, A., \& Cuadrado, R. M. (2008). Estudio sobre la enfermería comunitaria en el servicio madrileño de salud [A study of community nursing in the Madrid health service]. Madrid: Fundación Sindical de Estudios.

Germán, C. (2013). La revolución de las batas blancas: la enfermería española de 1976 a 1978 [The white coat revolution: nursing in Spain, 1976-1978]. Zaragoza: Prensas de la Universidad de Zaragoza.

Hayakawa, S. I., \& Hayakawa, A. (1990). Language in Thought and Action. New York: Harcourt Brace Jovanovich.

Hernández, J. M. (1995). Historia de la enfermería: un análisis histórico de los cuidados de enfermería [History of nursing: A historical analysis of nursing care]. Madrid: McGraw-Hill Interamericana de España.

Holt, J., Barrett, C., Clarke, D., \& Monks, R. (2000). The globalization of nursing knowledge. Nurse Education Today, 20(6), 426-431. doi:10.1054/nedt.2000.0497

Huch, M. H., \& Hisama, K. K. (2001). International perspectives. An eastern perspective and nursing theory. Nursing Science Quarterly, 14(3), 255-259 doi:10.1177/08943180122108373

Katz, J. (2001). Analytic induction. In N. J. Smelser \& P. B. Baltes (Eds.), International Encyclopedia of the Social and Behavioral Sciences (pp. 480-484). Oxford: Elsevier Science.

Kinsella, E. A. (2009). Original article. Professional knowledge and the epistemology of reflective practice. Nursing Philosophy, 11(5), 3-14. doi:10.1111/j.1466769X.2009.00428.X

Lister, P. (1997). The art of nursing in a "postmodern" context. Journal of Advanced Nursing, 25(1), 38-44. doi:10.1046/j.1365-2648.1997.1997025038.x

López-Parra, M. et al. (2006). Reflexiones acerca del uso y utilidad de los modelos y teorías de enfermería en la práctica asistencial [Reflections on the use and utility of nursing models and theories in health care practice]. Enfermería Clínica, 16(4), 218-221. doi:10.1016/S1130-8621(06)71217-7

Lunney, M., Parker, L., Fiore, L., Cavendish, R., \& Pulcini, J. (2004). Feasibility of studying the effects of using NANDA, NIC, and NOC on nurses' power and children's outcomes.Computers, Informatics, Nursing : CIN, 22(6), 316-325. 
Maggs, C. (1996). A history of nursing: a history of caring? Journal of Advanced Nursing, 23(3), 630-635. doi:10.111/j.1365-2648.1996.tb00028.x

Medina, J. L. (1999). La pedagogía del cuidado : saberes y prácticas en la formación universitaria en enfermería [The pedagogy of care: Knowledge and practice in a university-based nurse training]. Barcelona: Laertes.

Miró-Bonet, M. (2010). Los modelos conceptuales, una estrategia de poder con implicaciones profesionales [Conceptual models, a strategy of power with professional implications]. Enfermería Clínica, 20(6), 360-365. doi:10.1016/j.enfcli.2010.09.002

Miró-Bonet, M., Gastaldo, D., \& Gallego-Caminero, G. (2008). ¿Porqué somos como somos? Discursos y relaciones de poder en la constitución de la identidad profesional de las enfermeras en España (1956-1976) [Why are we as we are? Discourse and power relations in the construction of professional identity among Spanish nurses (1956-1976)]. Enfermería Clínica, 18(1), 26-34. doi:10.1016/S1130-8621(08)70690-9

Mitchell, G. (1991). Nursing diagnosis: An ethical analysis. Image: The Journal of Nursing Scholarship, 23(2), 99-104. doi:10.1111/j.1547-5069.1991.tb00651.x

Moorhead, S., \& Johnson, M. (2014). Clasificación de Resultados de Enfermería $(N O C)$ [Nursing Outcomes Classification (NOC)]. Barcelona: Elsevier Health Sciences.

Park, H. (1996). A history of nursing: a history of caring? Journal of Advanced Nursing, $23,630-635$.

Rousseau, N. (1997). From vocation to discipline. Canadian Nurse, 93(5), 39-44.

Santo-Tomás, M. (2000). Historia de la Enfermería [History of nursing]. In C.

Fernández Ferrín (Ed.), Enfermería Fundamental [Fundamentals of Nursing] (pp. 3-129). Barcelona: Masson.

Schön, D. A. (1987). Educating the reflective practitioner: Toward a new design for teaching and learning in the professions. San Francisco: Jossey-Bass.

Seidman, I. (2013). Interviewing as qualitative research : a guide for researchers in education and the social sciences. New York: Teachers College Press.

Sellán, M. C. (2010). La profesión va por dentro. Elementos para una historia de la Enfermería Española contemporánea [Inside the profession: Elements for a history of contemporary Spanish nursing] (2nd ed.). Madrid: FUDEN.

Shaw, M. C. (1993). The discipline of nursing: historical roots, current perspectives, future directions. Journal of Advanced Nursing, 18(10), 1651-1656. doi:10.1046/j.1365-2648.1993.18101651.x 
SmithBattle, L., \& Diekemper, M. (2001). Promoting clinical practice knowledge in an age of taxonomies and protocols. Public Health Nursing, 18(6), 401-408. doi: 10.1046/j.1525-1446.2001.00401.x

Strauss, A., \& Corbin, J. (2015). Basics of qualitative research: Techniques and procedures for developing grounded theory. Basics of qualitative research grounded theory procedures and techniques (Vol. 1). London: Sage Publications. doi:10.4135/9781452230153

Strauss, A., \& Corbin, J. (2002). Bases de la investigación cualitativa: técnicas y procedimientos para desarrollar la teoría fundamentada [Basics of qualitative research: techniques and procedures for developing grounded theory]. Medellín: Universidad de Antioquia.

Thorne, S., Kirkham,S.R. \& MacDonald-Emes, J. (1997). Focus on qualitative methods. Interpretative description: a noncategorical qualitative alternative for developing nursing knowledge. Res Nurs Health, 20, 169-177. doi: 10.1002/(SICI)1098240X(199704)20:2<169::AID-NUR9>3.0.CO;2-I

Thorne, S, Kirkham, S.R. \& O'Flynn-Magee, K. (2008). The analytic challenge in interpretative description. Int J Qual Methods, 3, 1-11. doi:10.1177/160940690400300101

Travale, I. (2007). Computer-Assisted instruction for novice nurses in critical care. The Journal of Continuing Education in Nursing, 38(3), 132-138. doi:10.3928/00220124-20070501-02

Warelow, P., Edward, K. L., \&Vinek, J. (2008). Care: what nurses say and what nurses do. Holistic Nursing Practice, 22(3), 146-153. doi:10.1097/01.HNP.0000318023.53151.33

Watson, J. (1997). The theory of human caring. Retrospective and prospective. Nursing science quarterly, 10(1), 49-52

Watson, J. (2006). Caring theory as an ethical guide to administrative and clinical practices. JONA'S Healthcare Law, Ethics and Regulation, 8(3), 87-93. doi: 10.1097/00128488-200607000-00008 


\section{Figure 1}

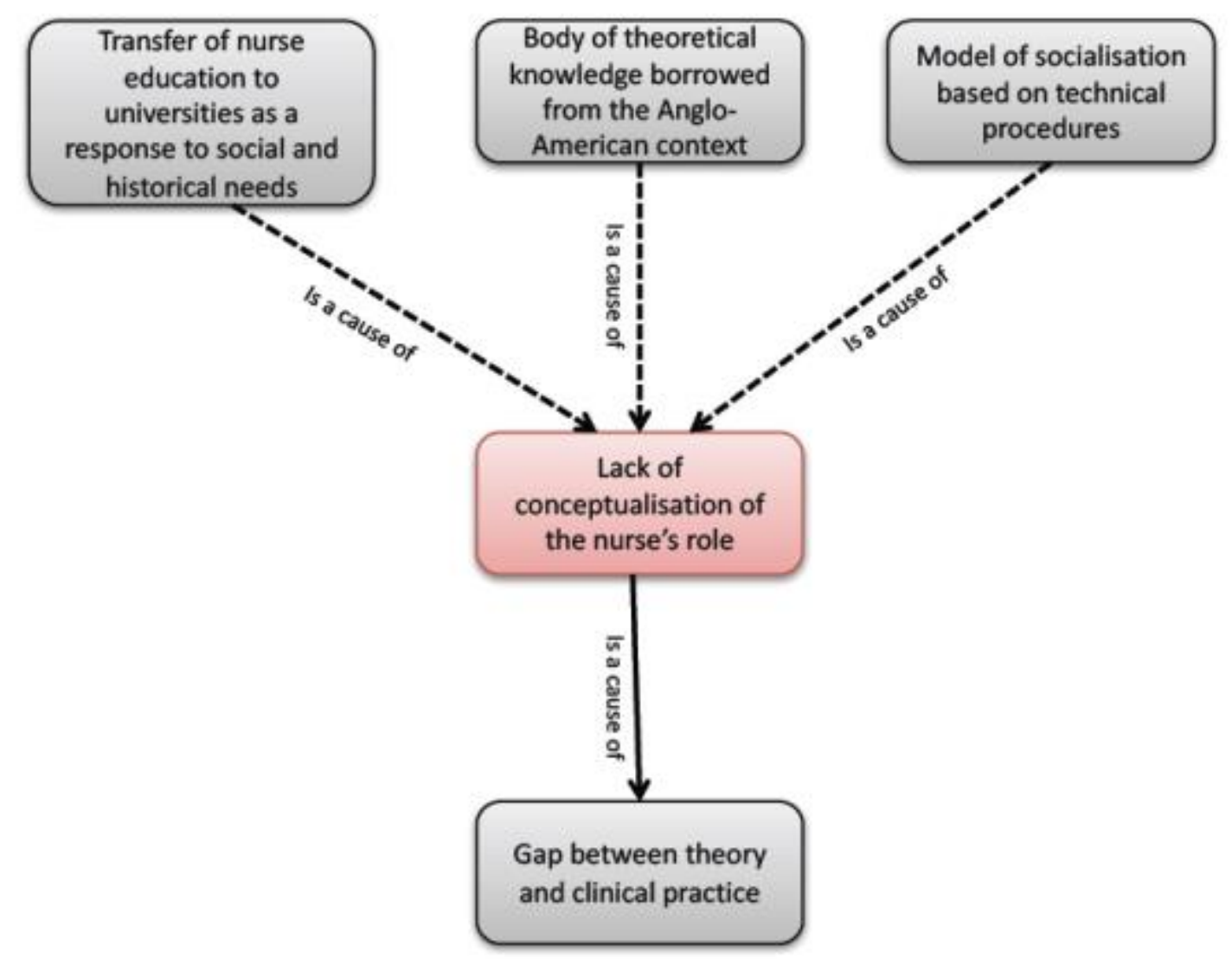


Table 1. Characteristics of the sample $(n=8)$

\begin{tabular}{l|c|l}
\hline Characteristics & $\begin{array}{c}\text { Number of } \\
\text { participants } \\
\text { from } \\
\text { among the } \\
\mathbf{n = 8}\end{array}$ & $\begin{array}{l}\text { Participant } \\
\text { number }\end{array}$ \\
\hline $\begin{array}{l}\text { Originally received the ATS qualification (Technical } \\
\text { Healthcare Assistant), and subsequently upgraded to the }\end{array}$ & 7 & $1,2,3,4,5,6,7$ \\
Diplomain Nursing & 1 & 2 \\
\hline Midwife & 1 & 8 \\
\hline Originally obtained the Diploma in Nursing & 3 & $1,3,4,6$ \\
\hline Graduate in other disciplines & 2 & $1,4,7$ \\
\hline PhD & 6 & $1,2,3,4,7,8$ \\
\hline Nurse tutor on aFundamentals of Nursing course & 2 & 5,6 \\
\hline Nurse tutor on a Nursing Management course & 2 & 3,6 \\
\hline Working in a public university & 5 & $1,4,5,7,8$ \\
\hline Working in a private university & 1 & 2 \\
\hline Working as a freelance nurse tutor & 2 & 3,6 \\
\hline Working in a non-religious university & 6 & $1,4,5,7,8$ \\
\hline Working in a Catholic university & 3 & $1,3,5$ \\
\hline Originally from Catalonia & 1 & 2 \\
\hline Originally from Valencia & 2 & 4,7 \\
\hline Originally from Andalusia & 1 & 6 \\
\hline Originally from the Balearic Islands & 6 & 8 \\
\hline Originally from Madrid & 1 & $1,2,3,4,5,6$ \\
\hline Female & 7,8 \\
\hline Male & 7 & \\
\hline Belonging to a religious order & 1 & \\
\hline & & \\
\hline
\end{tabular}

Table 2. Topics to be explored in the interviews.

\begin{tabular}{l|l}
\multicolumn{1}{c|}{ Operative Question } & \multicolumn{1}{c}{ Purpose of Exploring This Question } \\
\hline $\begin{array}{l}\text { Explain your personal background and } \\
\text { trajectory in becominga nurse. }\end{array}$ & Setting the experience in context. \\
\hline Explain your current experience as a nurse. & Reconstructing the details of experience in context. \\
\hline Explain what being a nurse means to you. & Meaning of the experience in context. \\
\hline
\end{tabular}

Source: Compiled from the model proposed by Seidman (2013) 